\title{
THE PREVALENCE OF CHRONIC HEPATITIS C IN PATIENTS PRESENTING WITH VAGUE RHEUMATIC SYMPTOMS IN A LOCAL COMMUNITY IN DISTRICT PUNJAB, PAKISTAN
}

\author{
Faheem Sarwar, Ghulam Murtaza, Sana Javed \\ Institution:Tehsil Headquarter Hospital, Sharaqpur Sharif, Sheikhupura - Pakistan
}

\begin{abstract}
Objective: This study was aimed to determine the prevalence of chronic hepatitis $C$ in patients presenting with vague rheumatic symptoms in a local community in district Punjab, Pakistan.

Materials and methods: A cross-sectional study was conducted in Tehsil Headquarter Hospital Sharaqpur Sharif, Sheikhupura, Pakistan. During a period of two and a half months, 751 patients presenting to general outdoor department with vague symptoms were selected through random sampling. People who presented with symptoms related to rheumatic dieases including, arthralgia, myalgia and lassitude without being explained on any other organic diseases, were labelled as vague symptoms. They were tested for Anti Hepatitis C Virus Antibodies, Hepatitis B Surface Antigen, and Anti Human Immunodeficiency Virus Antibodies with Rapid Immunochromatographic Test Kits. Statistical analysis was performed using IBM SPSS Statistics version 23.

Results: Of the 751 randomly selected patients, 28 were eliminated from results due to missing data and another 156 were removed on the basis of exclusion criteria. Out of 564 included participants, $37.8 \%$ were male and $62.2 \%$ were female with a mean age of $53.11 \pm 11.2$ years. Twenty-seven percent of people screened with vague symptoms were found to be positive for Hepatitis $C(N=152), 2.3 \%$ were Hepatitis $B(N=13)$, whereas only one was HIV positive.
\end{abstract}

Conclusion: This study suggests that Chronic Hepatitis $\mathrm{C}$ often present with vague rheumatic symptoms like arthralgia, myalgia and lassitude. Patients presenting with such symptoms and without underlying rheumatic diseases should be screened for hepatitis $\mathrm{C}$ virus infection.

Keywords: Chronic Hepatitis C, vague symptoms.

This article may be cited as: Sarwar F, Murtaza G, Javed S. The prevalence of chronic hepatitis C in patients presenting with vague rheumatic symptoms in a local community in district Punjab, Pakistan. J Med Sci 2021 July;29(3):116-119

\section{INTRODUCTION}

Hepatitis $\mathrm{C}$ infection is a global threat to health. Its prevalence is believed to be $2 \cdot 5 \%$ of the total world population (177.5 million), with the highest being in Central Asia and Central Africa (>3.5\%), moderate in the East, South and Southeast Asia, West and East Africa, North Africa and Middle East, Southern and Tropical Latin America, Caribbean, Australasia, and Eastern Europe (1.5\%-3.5\%) and relatively low (<1.5\%) in Southern Africa, North America, Andean and Central Latin America, Pacific Asia and Western and Central Europe ${ }^{1}$. However, in Pakistan there is great variability of prevalence with limited data available. According to the data currently available that includes

\section{Correspondence}

Dr. Faheem Sarwar

Medical Officer,

THQ Hospital, Sharaqpur Sharif, Sheikhupura - Pakistan

Email: dr.faheemsarwar@live.com

Cell: +92-321-5551451

Date received: $07-11-2020$

Date revised: $\quad 06-08-2021$

Date accepted: $08-08-2021$ both published and unpublished papers, prevalence in Pakistan among the general population is $6 \cdot 8 \%{ }^{2}$.

HCV has been a culprit of millions of deaths globally every year (1.3 million) ${ }^{3}$. Chronic hepatitis $C$ has served as a major distress for families by significantly reducing the quality of life ${ }^{4}$. However, not all patients suffer severe complications.5 In fact, the initial stage HCV infection is usually asymptomatic or mild. According to published studies, fatigue is the most common symptom of $\mathrm{HCV}$ infection followed by rheumatic symptoms like myalgia, arthralgia, lassitude, and depression ${ }^{6,-12}$. The initial mild nature results in a number of people to stay undiagnosed and remain chronic carriers. They are diagnosed when they develop signs and symptoms of liver failure ${ }^{13}$.

Despite being aware of these facts, educating people about the disease and performing screening tests still remains a challenge in Pakistan ${ }^{14}$. With overburdened hospitals and deficient investigative facilities, a large number of people are neglected. There are limited resources and lack of health facilities in the peripheral areas and that corresponds to the very high prevalence rates in rural areas ${ }^{15}$. Illiteracy and poor economic status add to this 
The Prevalence Of Chronic Hepatitis C In Patients Presenting With Vague Rheumatic Symptoms In A Local Community In...

misery and people do not focus on their health until they become very sick.

This study was focused on highlighting the prevalence of HCV infection in patients presenting with vague rheumatic symptoms such as lassitude, myalgia and arthralgia in the periphery of district Sheikhupura, Punjab, Pakistan.

\section{MATERIALS AND METHODS}

This cross-sectional study was conducted in Tehsil Headquarter Hospital Sharaqpur Sharif, a Secondary Level Hospital under Primary and Secondary Health Care Department, Government of Punjab. It is located in Tehsil Sharaqpur Sharif, a small town in District Sheikhupura of Punjab, Pakistan having a population of about 40,000 people. Minimum sample size calculated using OpenEpi Version 3 was 287 at 95\% confidence level. However, 751 participants were randomly selected from routine outdoor patients, who presented with vague rheumatic symptoms. For the purposes of the study "Vague symptoms" included myalgia, arthralgia, malaise and lassitude. Inclusion criteria for the study included, age above 40 years for both genders and rheumatic symptoms without organic explanation for those. Exclusion criteria included, overt jaundice and anemias, uncontrolled Diabetes Mellitus, Hypertension, Rheumatological disorders, and Hypothyroidism were ruled out on the basis of medical history and general physical examination. Those who met the inclusion criteria were briefed regarding the procedure of the study and informed consent was obtained. They were then screened for Hepatitis C Virus, Hepatitis B Virus and Human Immunodeficiency Virus with Rapid Immunochromatographic Test Kits, following manufacturer's instructions. Kits were manufactured by Vaxper Inc. Miami, FI, USA. For statistical analysis, SPSS version 23 was used.

\section{RESULTS}

Among a total 751 subjects, 28 were eliminated from results due to missing data and another 156 were removed due to exclusion criteria. Out of 564 included participants, $37.8 \%$ were males $(\mathrm{N}=213)$. Remaining $62.2 \%$ were females $(\mathrm{N}=351)$. The mean age of subjects is shown in Table 1. Hepatitis C Virus was detected in $26.95 \%$ subjects $(\mathrm{N}=152)$ out of which, $41.44 \%$ are males $(\mathrm{N}=63)$ and $58.55 \%$ are females $(\mathrm{N}=89)$. Gender-wise prevalence of Hepatitis $\mathrm{C}$ is shown in Figure 1. HBsAg was detected only in $2.3 \%$ people $(\mathrm{N}=13)$ out of which, 8 were female and 5 were male. Only one patient was positive for HIV antibodies. Comparison of prevalence of Hepatitis C and other viral infections is shown in Figure 2.

\section{DISCUSSION}

This study highlights a high prevalence of hepatitis $\mathrm{C}$ in the peripheral areas of Pakistan. Although internation-
Table 1: Mean Ages of the study participants

\begin{tabular}{|c|c|c|c|}
\hline & Mean & N & Standard deviation \\
\hline Male & 55.40 & 213 & $21 \cdot 12$ \\
\hline Female & 52.12 & 351 & $87 \cdot 10$ \\
\hline Total & 36.53 & 564 & $49 \cdot 11$ \\
\hline
\end{tabular}

\section{Hepatitis C Frequency}

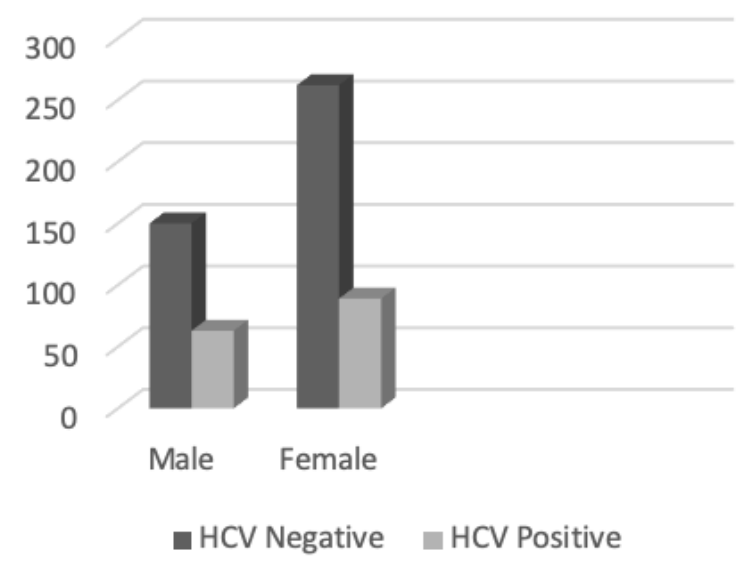

Fig 1: The frequency of HCV in males and females

\section{Comparison of Prevalence}

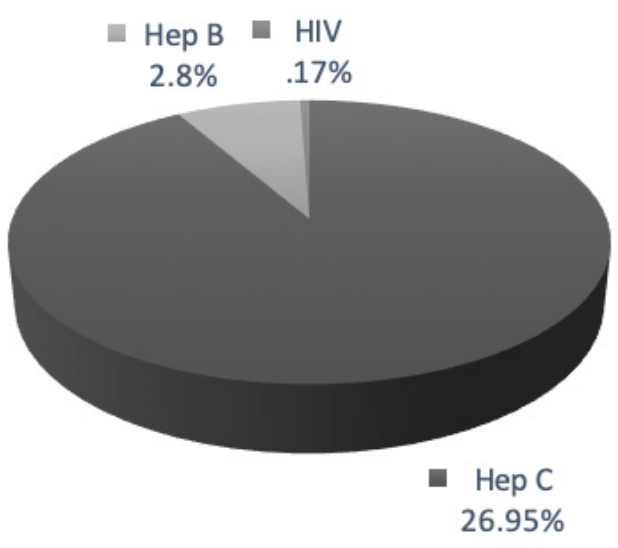

- Hep C Hep B $\quad$ HIV

Fig 2: Comparison of prevalence of HBV and HCV in
study population

al literature suggests a global decline in HCV prevalence in the past few years, this high prevalence and review of available material suggests that the incidence of HCV is still rising in Pakistan. This emphasizes the need for updating statistics. From 2010 to 2015 , there are only 86 studies on prevalence of HCV that includes published papers in indexed, non-indexed journals, and unpublished studies 
The Prevalence Of Chronic Hepatitis C In Patients Presenting With Vague Rheumatic Symptoms In A Local Community In...

as well ${ }^{2}$. It is noteworthy that there is high parity in this data. The overall prevalence in general population according to this data is $6.8 \%$ whereas it is reported to be $3.8 \%$ by the global prevalence studies published in indexed journals ${ }^{16}$.

Among the general population, Hepatitis $\mathrm{C}$ is presumed to be a serious disease but most people remain unaware of the symptoms and phases of the disease which is a major factor in delayed diagnosis and increased morbidity and mortality of hepatitis. Also, in overburdened healthcare setups, due to a deficiency of resources and the clinical impression of hepatitis $C$ being a moderate to severe disease notably in young doctors, many a times these patients get neglected. From this study, it is evident that a considerable proportion of people who presented with vague and mild rheumatic symptoms in the general out-patient departments were found to be positive for HCV. So, a more vigilant approach towards such patients is necessitated. Emphasis should be paid towards augmentation of clinical picture, symptoms and clustering of symptoms to improve diagnosis and overall management of Chronic Hepatitis C ${ }^{17}$.

The presence of vague and mild symptoms indicates a recent infection and curable stage of the disease. So, there is a dire need of expansion of hepatitis control program throughout the country, especially in peripheries, where people are relatively uninformed regarding this disease. This should include both screening and education to diagnose patients in time and stop the spread ${ }^{18}$.

Also, amidst the ongoing hepatitis control program throughout the province, this high prevalence is alarming. This calls for a need to check the efficacy of these control programs and reassess the strategies accordingly ${ }^{19}$. High prevalence of infection in people with a history of medical and surgical interventions along with blood transfusions is evident. That may be attributed to malpractice. There is a significant role of quacks who are involved in needle usage and unsafe use of intravenous drugs and surgical instruments ${ }^{20}$. Moreover, many hospitals also lack sufficient safety protocols and practice, including improper sterilization, lack of standard medical hygiene, careless handling, lack of proper disinfection, improper waste disposal, and untrained staff, which have been reported several times specifically in rural areas ${ }^{21}$. Strict and immediate action is required to develop updated SOP's and ensure strict compliance to stop the spread of hepatitis $C$ virus. A complete revamping of patient education system is necessary according to cultural requirements. Currently the main source of patient education for infectious diseases is print media to which a large population is unresponsive. Therefore, awareness should be given to people regarding the transmission, signs and symptoms, precautions, treatment, and complications in effective ways.

Various limitations of this study should be noted.
Firstly, we could not report prevalence of individual symptoms. Secondly, due to limitations in diagnostic facilities, we could not rule out certain other causes of fatigue and generalized body aches; such as Vitamin D3 levels and other chronic diseases ${ }^{22}$.

\section{CONCLUSION}

This study suggests that Chronic Hepatitis C often present with vague rheumatic symptoms like arthralgia, myalgia and lassitude. Patients presenting with such symptoms and without underlying rheumatic diseases should be screened for hepatitis $C$ virus infection.

\section{ACKNOWLEDGMENTS}

The completion of this study could not have been possible without the assistance of many people including Dr. Danish Islam and the Paramedical Staff at Tehsil Headquarter Hospital Sharaqpur Sharif. We would like to particularly thank Dr. Fatima Zaidi and Dr. Qanita Mahmud (Assistant Professor of Physiology, University College of Medicine) for reviewing and supervising the study.

\section{REFERENCES}

1. Petruzziello A, Marigliano S, Loquercio G, Cozzolino A, Cacciapuoti C. Global epidemiology of hepatitis $C$ virus infection: An up-date of the distribution and circulation of hepatitis $C$ virus genotypes. World journal of gastroenterology. 2016 Sep 14;22(34):7824.

2. Umer $M$, lqbal $M$. Hepatitis $C$ virus prevalence and genotype distribution in Pakistan: Comprehensive review of recent data. World journal of gastroenterology. 2016 Jan 28;22(4):1684.

3. World Health Organization. Progress report on HIV, viral hepatitis and sexually transmitted infections, 2019: annex 1: key data at a glance. World Health Organization; 2019.

4. Davis GL, Balart LA, Schiff E, Lindsay K, Bodenheimer Jr HC, Perrillo RP, Carey W, Jacobson IM, Payne J, Dienstag JL. Assessing health-related quality of life in chronic hepatitis C using the Sickness Impact Profile. Clinical therapeutics. 1994 Mar 1;16(2):334-43.

5. Kim WR, Brown Jr RS, Terrault NA, El-Serag H. Burden of liver disease in the United States: summary of a workshop. Hepatology. 2002 Jul;36(1):227-42.

6. Tong MJ, El-Farra NS. Clinical sequelae of hepatitis $\mathrm{C}$ acquired from injection drug use. Western journal of medicine. 1996 May;164(5):399.

7. Lee DH, Jamal H, Regenstein FG, Perrillo RP. Morbidity of chronic hepatitis $C$ as seen in a tertiary care medical center. Digestive diseases and sciences. 1997 Jan;42(1):186-91.

8. Desmet VJ, Gerber M, Hoofnagle JH, Manns M, Scheuer PJ. Classification of chronic hepatitis: diagnosis, grading and staging. Hepatology. 1994 Jun;19(6):1513-20.

9. Hoofnagle $\mathrm{JH}$. Hepatitis $\mathrm{C}$ : the clinical spectrum of disease. Hepatology. 1997 Dec;26(S3):15S-20S. 
The Prevalence Of Chronic Hepatitis C In Patients Presenting With Vague Rheumatic Symptoms In A Local Community In...

10. Gifford SM, O’BRIEN ML, Bammer G, Banwell C, Stoove M. Australian women's experiences of living with hepatitis $C$ virus: Results from a cross-sectional survey. Journal of gastroenterology and hepatology. 2003 Jul;18(7):84150 .

11. Cotler SJ, Wartelle CF, Larson AM, Gretch DR, Jensen $\mathrm{DM}$, Carithers Jr RL. Pretreatment symptoms and dosing regimen predict side-effects of interferon therapy for hepatitis C. Journal of viral hepatitis. 2000 May 1;7(3):211-7.

12. Barkhuizen A, Rosen HR, Wolf S, Flora K, Benner K, Bennett RM. Musculoskeletal pain and fatigue are associated with chronic hepatitis C: a report of 239 hepatology clinic patients. The American journal of gastroenterology. 1999 May 1;94(5):1355-60.

13. Moorman AC, Xing J, Ko S, Rupp LB, Xu F, Gordon SC, Lu M, Spradling PR, Teshale EH, Boscarino JA, Vijayadeva V. Late diagnosis of hepatitis $C$ virus infection in the Chronic Hepatitis Cohort Study (CHeCS): Missed opportunities for intervention. Hepatology. 2015 May;61(5):1479-84.

14. Jiwani N, Gul RB. A silent storm: hepatitis C in Pakistan. Journal of Pioneering Medical Sciences. 2011;1(3):89.

15. Alaei K, Sarwar M, Juan SC, Alaei A. Healthcare and the preventable silent Killer: the growing epidemic of hepatitis C in Pakistan. Hepatitis monthly. 2016 Nov;16(11).

16. Blach S, Zeuzem S, Manns M, Altraif I, Duberg AS, Muljono DH, Waked I, Alavian SM, Lee MH, Negro F, Abaalkhail F. Global prevalence and genotype distribution of hepatitis $C$ virus infection in 2015: a modelling study. The lancet Gastroenterology \& hepatology. 2017 Mar 1;2(3):161-76.

17. Miaskowski C, Dodd M, Lee K. Symptom clusters: the new frontier in symptom management research. $\mathrm{JNCl}$ Monographs. 2004 Jul;2004(32):17-21.

18. World Health Organization. Guidelines for the Screening Care and Treatment of Persons with Chronic Hepatitis C Infection Updated Version April 2016: Guidelines. World
Health Organization; 2016 Apr 30.

19. Graham CS, Swan T. A path to eradication of hepatitis C in low-and middle-income countries. Antiviral research. 2015 Jul 1;119:89-96.

20. Khan AJ, Luby SP, Fikree F, Karim A, Obaid S, Dellawala S, Mirza S, Malik T, Fisher-Hoch S, McCormick JB. Unsafe injections and the transmission of hepatitis $B$ and $\mathrm{C}$ in a periurban community in Pakistan. Bulletin of the World Health Organization. 2000;78:956-63.

21. Janjua NZ. Injection practices and sharp waste disposal by general practitioners of Murree, Pakistan. Journal of Pakistan Medical Association. 2003;53(3):107.

22. Roy S, Sherman A, Monari-Sparks MJ, Schweiker O, Hunter K. Correction of low vitamin D improves fatigue: effect of correction of low vitamin D in fatigue study (EViDiF Study). North American journal of medical sciences. 2014 Aug;6(8):396.

CONFLICT OF INTEREST: Authors declare no conflict of interest

GRANT SUPPORT AND FINANCIAL DISCLOSURE: NIL

\section{AUTHOR'S CONTRIBUTION}

Following authors have made substantial contributions to the manuscript as under

Sarwar F: $\quad$ Concept, Design and Proof reading

Murtaza G: Acquisition and critical review

Javad S: $\quad$ Analysis and interpretation of data

Authors agree to be accountable for all aspects of the work in ensuring that questions related to the accuracy or integrity of any part of the work are appropriately investigated and resolved. 